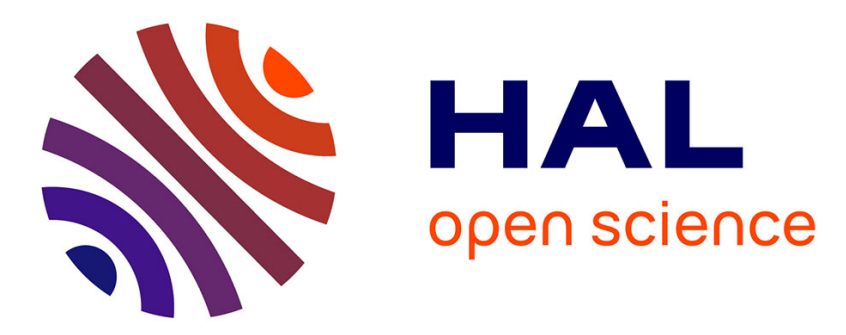

\title{
Investigation of the molecular signatures of selection on ATP synthase genes in the marine bivalve Limecola balthica
}

\author{
Eric Pante, Vanessa Becquet, Amélia Viricel, Pascale Garcia
}

\section{- To cite this version:}

Eric Pante, Vanessa Becquet, Amélia Viricel, Pascale Garcia. Investigation of the molecular signatures of selection on ATP synthase genes in the marine bivalve Limecola balthica. Aquatic Living Resources, 2019, 32, pp.3. 10.1051/alr/2019001 . hal-02383588

HAL Id: hal-02383588

https://hal-univ-rochelle.archives-ouvertes.fr/hal-02383588

Submitted on 8 Nov 2020

HAL is a multi-disciplinary open access archive for the deposit and dissemination of scientific research documents, whether they are published or not. The documents may come from teaching and research institutions in France or abroad, or from public or private research centers.
L'archive ouverte pluridisciplinaire HAL, est destinée au dépôt et à la diffusion de documents scientifiques de niveau recherche, publiés ou non, émanant des établissements d'enseignement et de recherche français ou étrangers, des laboratoires publics ou privés. 
1 Investigation of the molecular signatures of selection on ATP synthase genes in the marine

2 bivalve Limecola balthica

3 Eric Pante ${ }^{1 *}$, Vanessa Becquet ${ }^{1}$, Amélia Viricel ${ }^{1}$, and Pascale Garcia ${ }^{1}$

$41^{1}$ Littoral, Environnement et Sociétés (LIENSs), UMR 7266 CNRS - Université de La Rochelle, 2 rue

5 Olympe de Gouges, 17000 La Rochelle, France * Corresponding author. E-mail: epante@univ-lr.fr;

6 Phone: +33.05.46.50.76.37; Fax: +33.05.46.50.76.63.

\section{Abstract}

8 We used transcriptomic sequence data to describe patterns of divergence and selection across

9 different populations of a marine bivalve (Limecola balthica). Our analyses focused on a nuclear

10 gene $(a t p 5 c 1)$ that was previously detected in an $F_{\mathrm{ST}}$ scan as highly structured among populations

11 separated by the Finistère Peninsula in France. This gene encodes the gamma subunit of the $\mathrm{FO}_{0} / \mathrm{F}_{1}$

12 ATP synthase, a multi-protein complex that is paramount to cellular respiration and energy

13 production. Analysis of non-synonymous to synonymous mutation ratios revealed that $65 \%$ of the

14 gene is highly conserved $(\mathrm{dN} / \mathrm{dS} \leq 0.1$, min $=0)$, while $6 \%$ of the gene is likely under positive

15 selection $(\mathrm{dN} / \mathrm{dS} \geq 1, \max =2.03)$. All replacement mutations are clustered on a 46 residues portion

16 of the protein, within an inter-peptide interaction zone. Comparative genomics suggests that these

17 mutations are evolutionarily stable, and we hypothesize that they are involved in inter-population

18 genetic incompatibilities with other subunits of the ATP synthase complex. The protein stability of

19 the gamma subunit conferred by southern variants was inferred to be higher under warmer

20 temperatures, suggesting that environmental conditions may contribute to the strength of genetic

21 barriers in L. balthica.

22 Keywords: Molecular evolution; local adaptation; genetic incompatibilities; selection; ATP

23 synthase; Macoma balthica

24 Running title: Barriers to gene flow in Limecola balthica 
27 It is now well-accepted that marine organisms can show local adaptation to environmental

28 conditions despite their high dispersal potential, which was long thought to prevent adaptive

29 differentiation (e.g. review of Sanford and Kelly 2011). In fact, recent research has shown that

30 adaptations can emerge and be maintained in spite of gene flow (Tigano \& Friesen 2016). For

31 instance, focusing on the high-gene flow sea urchin Strongylocentrotus purpuratus, Pespeni et al

32 (2013) found evidence for local adaptation to temperature in an environmental mosaic, at multiple

33 protein-coding genes that were previously detected using a genome scan.

34 Limecola balthica is a highly dispersive marine bivalve, broadly distributed in the northwestern

35 Europe (Väinölä and Varvio, 1989). Its pelagic larval phase is estimated to last 2 to 5 weeks (Caddy

36 1967). In the Northern Atlantic Ocean, two lineages of L. balthica occur, due to multiple events of

37 trans-arctic dispersal from the northern Pacific Ocean (Väinölä 2003, Nikula et al 2007). A Pacific

38 lineage (L. balthica balthica) occurs in the White and Baltic Seas, and an Atlantic lineage (L. balthica

39 rubra) is found along the Atlantic coasts from Norway to France and around the British Isles

40 (Väinölä 2003; Luttikhuisen et al 2003; Nikula et al 2007; Becquet et al 2012). The rubra lineage

41 extends to the Gironde Estuary, France (with sparse populations down to Arcachon Basin), which

42 corresponds to the present-day range limit for the species (Bachelet 1980). A hybrid zone between

43 rubra and balthica was detected at the entrance of the Baltic Sea (Kattegat Strait; Nikula et al 2008).

44 Within rubra, populations north and south of the Finistère Peninsula (France) show significant

45 mitochondrial and nuclear (microsatellite loci) genetic differentiation (Figure 1b; Becquet et al

46 2012).

47 An $F_{\mathrm{ST}}$-based genome scan was performed on transcriptomic data from pooled individuals, across

48 the Kattegat and Finistère transition zones, in a preliminary effort to look for loci associated with

49 local adaptation (Pante et al 2012). Three geographically-disjunct populations were sampled

50 (Figure 1a). The sites of Aytré (Bay of Biscay, France) and Somme Bay (English Channel, France)

51 correspond to two discrete populations of the rubra lineage (Becquet et al., 2012). Aytré is located

52 near the southern limit of the species distributional range and is characterized by warmer sea

53 surface temperatures than Somme Bay (Figure 1b). Furthermore, the Bay of Biscay is subjected to

54 warming surface water temperatures (Goikoetxea et al., 2009). A third population, corresponding to

55 the balthica lineage, was sampled in Gdańsk Bay (Baltic Sea, Poland). This $F_{\text {ST }}$ Scan revealed multiple

56 genes involved in the oxidative phosphorylation (OXPHO) system (including genes coding for

57 subunits of the Fo/F1 ATP synthase and NADH dehydrogenase complexes, and an ADP/ATP 
carrier). In particular, the nuclear gene atp $5 c 1$ encoding the gamma subunit of the ATP synthase F1

59 rotor, may be under strong selection: 23/41 mapped SNPs were detected as $F_{\text {ST }}$ outliers (maximum

$\left.60 F_{\mathrm{ST}}=0.838\right)$. This gene is paramount to the good functioning of the Fo/F1 complex, as its rotary

61 action promotes ATP synthesis (reviewed in Sielaff and Börsch, 2013).

62 In this contribution, we examine molecular signatures of selection at atp $5 c 1$ by further analysing the

63 transcriptomic data of Pante et al (2012). Our goals were to determine whether SNPs that are highly

64 differentiated among populations cause modifications of the protein structure, and whether these

65 changes may have functional repercussions. Given that the FO/F1 complex is generally encoded by

6612 nuclear and 2 mitochondrial genes (reviewed in Rand et al., 2004), we asked whether high- $F_{\mathrm{ST}}$,

67 non-synonymous mutations fall within predicted sites of inter-protein interactions, suggesting the

68 implication of genetic incompatibilities in maintaining barriers to gene flow between southern and

69 northern populations of L. balthica.

\section{$71 \quad$ Material and Methods}

72 Specimen sampling, and preparation of genetic data

73 cDNA libraries were prepared from three pools of 10 individuals (one pool per site) and sequenced

74 on a Roche 454 GS-FLX. Details on sequence quality control and assembly, read mapping,

75 polymorphism detection, and gene annotation can be found in Pante et al. (2012). Here we focus on

76 contig G_c113, detected in this latter study, and identified as coding for atp $5 c 1$ (characterized in

77 Matsuda et al., 1993).

78 Sequence evolution and predicted changes in protein function

79 Differences in allele frequencies between population pairs were tested with Fisher's Exact tests, using

80 Popoolation2 (Kofler et al 2011). The molecular signature of selection was investigated by looking at

81 the ratio between non-synonymous (dN) and synonymous (dS) substitutions (e.g. Kimura, 1977),

82 calculated using the R package seqinr (Charif and Lobry, 2007). A sliding window (150 nt wide,

83 sliding every $3 \mathrm{nt}$ ) was used to detect variation in this ratio along the gene. $\mathrm{dN} / \mathrm{dS}$ ratios were

84 calculated based on population sequence consensuses, as in Barreto et al. (2011). The programs

85 SIFT (Kumar et al., 2009; Ng and Henikoff, 2006) and SNAP (Bromberg and Rost, 2007) were used

86 to test whether variations in amino-acid (AA) compositions may have an impact on protein function. 
87 SIFT predicts whether AA substitutions can be tolerated by aligning and comparing homologous

88 sequences retrieved by PSI-Blast; protein structure is not taken into account. SNAP uses sequence

89 information, but can incorporate functional and structural annotations if such data are available

90 (Bromberg and Rost, 2007). In SIFT, median conservation of sequences was set at 3.00 and

91 sequences $\geq 90 \%$ identical to the query were removed. The hypothesis that local environmental

92 conditions, such as sediment temperature and $\mathrm{pH}$, affect the stability of different alleles of atp $5 c 1$

93 was tested using I-Mutant 2.0 (Capriotti et al., 2005). Protein stability $(\Delta \Delta G)$ was estimated at 5, 15,

94 and $30^{\circ} \mathrm{C}$, and at $\mathrm{pH} 6,7$, and 8 (conditions based on observed data; Ekebom, 1999 and Lavergne

95 and Barnett, personal communication). In order to further evaluate the impact of AA mutations on

96 protein function, the structure of the gamma subunit was predicted using the I-TASSER server (Roy

97 et al., 2010; Zhang, 2008) and visualized with the UGENE toolkit (Okonechnikov et al., 2012).

98 Finally, we looked for non-synonymous mutations in the other nuclear-encoded $\mathrm{F}_{0} / \mathrm{F}_{1}$ ATP synthase

99 subunits that could be detected in the transcriptome.

\section{Results}

101 Replacement mutations on atp5c1

102 Amino acid sequences of atp5c1 from populations sampled some $2800 \mathrm{~km}$ apart are, overall, highly

103 conserved, with a global dN/dS ratio of 0.08 . The sliding window analysis (150 nt wide, sliding

104 every codon; Figure $2 \mathrm{a})$ revealed that $65 \%$ of the gene is under negative selection $(\mathrm{dN} / \mathrm{dS} \leq 0.1, \min$

$105=0)$, while $6 \%$ of the gene is under positive selection $(\mathrm{dN} / \mathrm{dS} \geq 1, \max =2.03)$. Five AA changes

106 occur between residues 126 and 171, meaning that non-synonymous changes are clustered within a

107 46-residue fragment spanning 15\% of the sequence. This region was predicted by I-TASSER (best

108 model C-score = 0.04; Figure $2 \mathrm{~b}$ ) to overlap with two known peptide binding sites (Protein Data

109 Bank IDs 2W6I and 2HLD; C-scores of 0.09 and 0.07, respectively). CDD annotation (Conserved

110 Domains Database, Marchler-Bauer et al., 2013) following a BLASTX (Altschul et al., 1990) search

111 for G_c113 suggest that these mutations occur at the interface with the core domain (interaction

112 with the alpha-beta hexamere) and with the epsilon subunit. These non-synonymous changes were

113 predicted to be evolutionarily tolerated based on SIFT and SNAP (expected SNAP accuracy 85-94\%).

114 The first four AA changes (L126A, N131D, D136N, H156D; nomenclature: Aytré considered as

115 mutant) discriminate Aytré from Gdańsk Bay and Somme Bay, while the fifth one (T171S)

116 distinguishes Gdańsk from the two French populations. N131D and H156D have a stabilizing effect

117 on the protein, while all others have a destabilizing effect (I-Mutant tests between 15 and $30^{\circ} \mathrm{C}$ at

118 pH7; Figure 3). In all cases, a relative increase in $\Delta \Delta \mathrm{G}$ was observed with increasing temperature 
119 and $\mathrm{pH}$ (i.e., in warmer conditions, a destabilizing mutation was less destabilizing). In one case

120 (N131D), $\Delta \Delta \mathrm{G}$ changed sign (from negative to positive) with increased temperature (in all $\mathrm{pH}$

121 conditions), indicating that the expected effect of the mutation shifted from destabilizing to

122 stabilizing. Considering the 4 AA mutations described above, the Aytré population contained a mix

123 of two alleles, the major allele (85.5\% of the reads) being unique to Aytré and one corresponding to

124 the type found at Somme and Gdańsk (14.5\% of the reads). The median depth of coverage for contig

125 G_c113 was 55, 45 and 18 for Aytré, Gdańsk and Somme, respectively (Table 1).

126 Potential for incompatibilities with other ATP synthase subunits

127 Contig G c1077 was identified as coding for the alpha subunit and bear one outlier $F_{\mathrm{ST}}$ when 128 comparing the samples from Aytré and Somme $\left(F_{\mathrm{ST}}=0.672\right.$, Pante et al., 2012). This contig could be 129 reliably placed in ORF, which revealed that all nine mutations were synonymous. All mutations 130 segregated Aytré from Somme and Gdańsk. Several contigs were identified as coding for the beta 131 subunit; one (A c2900) was included in our initial $F_{\mathrm{ST}}$ scan but did not stand out as bearing outlier 132 SNPs (in addition, this contig could not be reliably placed in ORF). Unfortunately, the epsilon 133 subunit could not be detected in our transcriptome dataset.

\section{Discussion}

135 Adaptive divergence at OXPHO loci

136 Mitochondrial function can be significantly influenced by temperature (e.g. Dahlhoff and Somero, 137 1993). In Dutch populations of L. balthica, respiration rate was shown to increase with temperature 138 intra-seasonally (Hummel et al., 2000). In addition, Dutch specimens transplanted in the Spanish 139 estuary of Bidasoa, $200 \mathrm{~km}$ south of the known species range limit (i.e. the Gironde Estuary, some $14080 \mathrm{~km}$ from our sampling site in Aytré, France) showed respiration rates significantly higher than in 141 their native populations (Hummel et al., 2000). Our analyses on the effect of temperature on the 142 stability of subunit gamma suggest a small, positive effect of each replacement mutation in the 143 southern population. While only five replacement mutations were detected, previous studies have 144 shown that even few differences in amino acid composition can have a significant impact on 145 mitochondrial performance. In the marine copepod Tigriopus californicus, three amino acid changes 146 at the nuclear cytochrome c, separating populations characterized by different thermal regimes, 147 correlated with significant differences in cytochrome c oxidase activity (Rawson and Burton, 2002).

148 In the seed beetle Callosobruchus maculatus, metabolic rates were detected between cytotypes that 
149 differed by one amino acid at COI and one amino acid at Cyt-B (Arnqvist et al., 2010, and see below).

150 In killer whales (Orcinus orca), single amino acid changes at Cyt-B are associated with Antarctic

151 ecotypes, and are therefore possibly implicated in improved mitochondrial performance in polar

152 waters (Foote et al., 2011). Cyt-B was also recently implicated in thermal adaptation in the

153 European anchovy (Silva et al., 2014). Finally, the synergistic impact of temperature and few

154 replacement mutations on protein stability and function was recorded the nuclear locus encoding

155 cytoplasmic malate dehydrogenase (cMDH) in limpets (Dong and Somero, 2009). As the surface

156 water of the Bay of Biscay is known to be warming at rate of $0.26^{\circ} \mathrm{C} /$ decade $(1977-2007$ time

157 period, Goikoetxea et al., 2009) and the geographical range (Jansen et al., 2007) of southern $L$.

158 balthica is thought to be receding, it becomes increasingly important from a conservation

159 standpoint to understand how genetic diversity at OXPHO genes relates to adaptive potential.

160 Indeed, as gene flow is limited between southern and northern rubra populations at atp $5 c 1$, a

161 narrowing geographical range could result in the loss of adaptive alleles if the southern population

162 does not persist.

163 Implications for intrinsic genetic incompatibilities among ATP synthase subunits

164 Our data suggest that five replacement mutations may interact with other subunits, likely epsilon

165 (encoded by atp5e in humans, Tu et al., 2000). This subunit sits on the Fo stator, which is composed

166 of nuclear- and mitochondrial-encoded genes and is embedded in the mitochondrial membrane.

167 While atp5e was not detected in our dataset, characterizing genetic variation at atp $5 e$ and other ATP

168 synthase subunits (including mitochondrial and nuclear ones) across the Finistère transition zone

169 seems central to understanding how intrinsic genetic incompatibilities are involved in maintaining

170 barriers to gene flow in L. balthica. The sequencing of mitochondrial genomes from individuals

171 sampled on either sides of the Baltic and Finistère hybrid zones (Saunier et al., 2014) will help us

172 shed some light on possible incompatibilities between the nuclear and mitochondrial genes coding

173 for ATP synthase subunits. In addition, the recent discovery of sex-linked heteroplasmy in $L$.

174 balthica suggests that mitochondria in this species are characterised by Doubly Uniparental

175 Inheritance (DUI; Pante et al., 2017, and unpublished male mitogenome draft). In DUI species, the

176 somatic tissues of males are characterized by a 'female' mitotype (as in all tissues of females), while

177 the male germ line is characterized by a 'male' mitotype that is passed on from fathers to sons

178 (reviewed in Zouros, 2013). Female and male mitotypes sampled from a single individual can be

179 highly divergent, reaching up to 52\% in freshwater unionoid mussels (Doucet-Beaupré et al 2010).

180 In L. balthica, genetic incompatibilities could therefore occur in multiple ways, as OXPHO epistatic 
181 interactions among nuclear genes, nuclear and female mitochondrial genes, and among nuclear and

182 male mitochondrial genes in the sperm of interpopulational hybrids.

183 Interplay between intrinsic genetic incompatibilities and temperature

184 One fascinating avenue for research is the characterization of interactions between intrinsic genetic

185 incompatibilities and extrinsic environmental forces. Arnqvist et al. (2010) were the first to

186 demonstrate environmental effects on mitonuclear epistatic interactions by crossing mitochondrial

187 and nuclear genomes of C. maculatus. In this very elegant experiment, the authors showed that the

188 negative effects of genetic incompatibilities on metabolic rate were only detectable when hybrids

189 were exposed to different temperatures (Arnqvist et al., 2010). In L. balthica, the replacement

190 mutations mapped on atp5c1 (i) are located in an inter-peptide interaction zone (most likely in the

191 area were the gamma subunit interacts with epsilon), and (ii) seem to influence the stability of the

192 gamma subunit depending on temperature and pH. This preliminary study is based on very limited

193 data, as we used few, pooled individuals from three populations to investigate the molecular

194 signatures of selection on atp $5 c 1$. Future research should therefore focus on determining, with

195 larger population sampling, if subunits of the Fo/F1 ATP synthase complex are indeed involved in

196 mitonuclear genetic incompatibilities enforcing genetic barriers, and whether these putative

197 incompatibilities are affected by the environment.

\section{Acknowledgements}

199 We thank Patrick Triplet, Antoine Meirland (Association GEMEL, Picardie) and Rafal Lasota for

200 specimen collections, and the Molecular Core Facility at the University of La Rochelle. We also thank

201 two anonymous reviewers for improving the manuscript. This work was funded by the French

202 Agence Nationale de la Recherche (Hi-Flo project ANR-08-BLAN-0334; HySea project ANR-12-BSV7-

203 0011); salary for EP was covered by a “Contrat de Projet Etat-Région." Funding from the Université

204 de La Rochelle (ACI JCJC) allowed the authors to present at PhysioMar17.

\section{References}

206 Altschul, S., Gish, W., Miller, W., Myers, E., and Lipman, D. (1990). Basic local alignment search tool. 207 Journal of Molecular Biology, 215:403-410.

208 Arnqvist, G., Dowling, D., Eady, P., Gay, L., Tregenza, T., Tuda, M., and Hosken, D. (2010). Genetic 209 architecture of metabolic rate: environment specific epistasis between mitochondrial and 
nuclear genes in an insect. Evolution, 64(12):3354-3363.

211 Bachelet, G. (1980). Growth and recruitment of the tellinid bivalve Macoma balthica at the southern 212 limit of its geographical distribution, the Gironde Estuary (SW France). Marine Biology 59, $213 \quad 105-117$.

214 Barreto, F. S., Moy, G. W., and Burton, R. S. (2011). Interpopulation patterns of divergence and selection across the transcriptome of the copepod Tigriopus californicus. Molecular Ecology, 20(3):560-572.

Becquet, V., Simon-Bouhet, B., Pante, E., Hummel, H., and Garcia, P. (2012). Glacial refugium versus range limit: conservation genetics of Macoma balthica, a key species in the Bay of Biscay (France). Journal of Experimental Marine Biology and Ecology, 432-433:73-82.

Bromberg, Y. and Rost, B. (2007). SNAP: predict effect of non-synonymous polymorphisms on function. Nucleic Acids Research, 35(11):3823-3835.

Caddy, J.F. (1967). Development of mantle organs, feeding and locomotion in postlarval Macoma balthica (L.) (Lamellibranchiata). Canadian Journal of Zoology. 47, 609-617.

224 Capriotti, E., Fariselli, P., and Casadio, R. (2005). I-Mutant2.0: predicting stability changes upon 225 mutation from the protein sequence or structure. Nucleic Acids Research, 33(Web Server 226 issue):W306-10.

Charif, D. and Lobry, J. (2007). SeqinR 1.0-2: a contributed package to the R project for statistical computing devoted to biological sequences retrieval and analysis. In Bastolla, U., Porto, M., Roman, H., and Vendruscolo, M., editors, Structural approaches to sequence evolution: Molecules, networks, populations, Biological and Medical Physics, Biomedical Engineering, pages 207-232. Springer Verlag, New York.

Dahlhoff, E. and Somero, G. (1993). Effects of temperature on mitochondria from abalone (genus Haliotis): adaptive plasticity and its limits. Journal of Experimental Biology, 185:151-168. correlate with biogeographic and vertical distributions. Journal of Experimental Biology, 
238 Doucet-Beaupré H., Breton S., Chapman E.G., Blier P.U., Bogan A.E., Stewart D.T. and Hoeh W.R. 239 (2010). Mitochondrial phylogenomics of the Bivalvia (Mollusca): searching for the origin and mitogenomic correlates of doubly uniparental inheritance of mtDNA. BMC Evolutionary Biology 201010:50 doi:10.1186/1471-2148-10-50.

Ekebom, J. (1999). Heterotrophic nanoflagellates and bacteria in sediment of a brackish water sill basin in the Baltic Sea. Hydrobiologia, 393:151161.

Foote, A. D., Morin, P. A., Durban, J. W., Pitman, R. L., Wade, P., Willerslev, E., Gilbert, M. T. P., and da Fonseca, R. R. (2011). Positive selection on the killer whale mitogenome. Biology Letters, $7(1): 116-118$.

Goikoetxea, N., Borja, A., Fontán, A., González, M., and Valencia, V. (2009). Trends and anomalies in sea surface temperature, observed over the last 60 years, within the southeastern Bay of Biscay. Continental Shelf Research, 29:1060-1069. respiratory performance and survival of the bivalve Macoma balthica (L.) at the southern limit of its distribution area: a translocation experiment. Journal of Experimental Marine Biology and Ecology, 251:85-102.

Jansen, J. M., Pronker, A. E., Bonga, S. W., and Hummel, H. (2007). Macoma balthica in Spain, a few decades back in climate history. Journal of Experimental Marine Biology and Ecology, 344:161-169.

Kimura, M. (1977). Preponderance of synonymous changes as evidence for the neutral theory of molecular evolution. Nature, 267:275-276.

259 Kofler, R., Vinay Pandey, R. and Schlötterer, C. (2011) PoPoolation2: Identifying differentiation between populations using sequencing of pooled DNA samples (Pool-Seq). Bioinformatics, $27(24): 3435-3436$. variants on protein function using the SIFT algorithm. Nature Protocols, 4(7):1073-1081.

264 Luttikhuizen P.C., Drent J., Baker A.J. (2003) Disjunct distribution of highly diverged mitochondrial 265 lineage clade and population subdivision in a marine bivalve with pelagic larval dispersal. 
Molecular Ecology 12:2215-2229.

267 Marchler-Bauer, A., Zheng, C., Chitsaz, F., Derbyshire, M. K., Geer, L. Y., Geer, R. C., Gonzales, N. R., 268 Gwadz, M., Hurwitz, D. I., Lanczycki, C. J., Lu, F., Lu, S., Marchler, G. H., Song, J. S., Thanki, N., 269 Yamashita, R. A., Zhang, D., , and Bryant, S. H. (2013). CDD: conserved domains and protein three-dimensional structure. Nucleic Acids Research, 41(D1):D348-D352.

271 Matsuda, C., Endo, H., Ohta, S., and Kagawa, Y. (1993). Gene structure of human mitochondrial ATP synthase gamma-subunit. Tissue specificity produced by alternative RNA splicing. Journal of Biological Chemistry, 268(33):24950-24958.

Ng, P. C. and Henikoff, S. (2006). Predicting the effects of amino acid substitutions on protein function. Annual Review of Genomics and Human Genetics, 7:61-80.

Nikula, R., P. Strelkov, and R. Väinölä. 2007. Diversity and trans-arctic invasion history of mitochondrial lineages in the North Atlantic Macoma balthica complex (Bivalvia: Tellinidae). Evolution 61:928-941.

Nikula, R., P. Strelkov, and R. Väinölä. 2008. A broad transition zone between an inner Baltic hybrid swarm and a pure North Sea subspecies of Macoma balthica (Mollusca, Bivalvia). Molecular Ecology 17:1505-22.

Okonechnikov, K., Golosova, O., Fursov, M., and UGENE team (2012). Unipro UGENE: a unified bioinformatics toolkit. Bioinformatics, 28(8):1166-1167.

Pante, E., Poitrimol, C., Saunier, A., Becquet, V., and Garcia, P. (2017). Putative sex-linked heteroplasmy in the tellinid bivalve Limecola balthica (linnaeus, 1758). Journal of Molluscan Studies, 83(2):226-228.

Pante, E., Rohfritsch, A., Becquet, V., Belkhir, K., Bierne, N., and Garcia, P. (2012). SNP detection from De Novo transcriptome sequencing in the bivalve Macoma balthica: marker development for evolutionary studies. PLoS ONE, 7(12):e52302.

Pespeni M.H., Palumbi S.R. (2013). Signals of selection in outlier loci in a widely dispersing species across an environmental mosaic. Molecular Ecology 22:3580-3597. 
Trends in Ecology \& Evolution, 19(12):645-53.

294 Rawson, P. D. and Burton, R. S. (2002). Functional coadaptation between cytochrome c and cytochrome c oxidase within allopatric populations of a marine copepod. Proceedings of the National Academy of Sciences of the United States of America, 99(20):12955-12958.

Reynolds, R. W., Smith, T. M., Liu, C., Chelton, D. B., Casey, K. S., and Schlax, M. G. (2007). Daily highresolution-blended analyses for sea surface temperature. Journal of Climate, 20:5473-5496.

Roy, A., Kucukural, A., and Zhang, Y. (2010). I-TASSER: a unified platform for automated protein structure and function prediction. Nature Protocols, 5(4):725-738.

Sanford E., Kelly M.W. (2011). Local Adaptation in Marine Invertebrates Annual Review of Marine Science 3:509-535.

Saunier, A., Garcia, P., Becquet, V., Marsaud, N., Escudié, F., and Pante, E. (2014). Mitochondrial genomes of the Baltic clam Macoma balthica (Bivalvia: Tellinidae): setting the stage for studying mito-nuclear incompatibilities. BMC Evolutionary Biology, 14:259.

Sielaff, H. and Börsch, M. (2013). Twisting and subunit rotation in single FOF1-ATP synthase. Philosophical Transactions of the Royal Society of London. Series B, Biological Sciences, 368:1471-2970.

Silva, G., Lima, F. P., Martel, P., and Castilho, R. (2014). Thermal adaptation and clinal mitochondrial DNA variation of European anchovy. Proceedings of the Royal Society of London Series BBiological Sciences, 281(1792).

Tigano A., Friesen V.L. (2016). Genomics of local adaptation with gene flow. Molecular Ecology 25:2144-64.

314 Tu, Q., Yu, L., Zhang, P., Zhang, M., Zhang, H., Jiang, J., Chen, C., and Zhao, S. (2000). Cloning, characterization and mapping of the human ATP5E gene, identification of pseudogene ATP5EP1, and definition of the ATP5E motif. Biochemical Journal, 347:17-21.

Väinölä, R. 2003. Repeated trans-Arctic invasions in littoral bivalves: molecular zoogeography of the Macoma balthica complex. Marine Biology 143:935-946. 
320 Ryland, J. and Tyler, P., editors, Reproduction, genetics and distributions of marine organisms, 321 23rd Eur Mar Biol Symp, pages 309-316, Fredensborg. Olsen and Olsen.

322 Zhang, Y. (2008). I-TASSER server for protein 3D structure prediction. BMC Bioinformatics, 9:40.

323 Zouros, E. (2013). Biparental inheritance through uniparental transmission: the doubly

324 uniparental inheritance (DUI) of mitochondrial DNA. Evolutionary Biology, 40:1-31.

325 Zouros E (2013) Biparental inheritance through uniparental transmission: The Doubly Uniparental 326 Inheritance (DUI) of Mitochondrial DNA. Evolutionary Biology, 40: 1-31. 
327 Table 1. Read counts at each position of codons containing non-synonymous mutations, for each

328 population. The significance of differences in allele frequencies are presented as - $\log 10$ of p-values

329 from Fisher's Exact tests (significance for at least one pair of populations: *: $-\log 10(\mathrm{p})>1$; **: -

$330 \log 10(\mathrm{p})>10)$.

331

\begin{tabular}{|c|c|c|c|c|c|c|c|c|c|c|c|}
\hline \multirow[b]{2}{*}{ Locus } & \multirow[b]{2}{*}{ Pos } & \multicolumn{2}{|c|}{ Aytré (A) } & \multicolumn{2}{|c|}{ Somme (S) } & \multicolumn{2}{|c|}{ Gdansk (G) } & \multicolumn{4}{|c|}{$\begin{array}{l}\text { Fisher's Exact } \\
\text { Test }\end{array}$} \\
\hline & & Major & Minor & Major & Minor & Major & Minor & A-S & A-G & S-G & \\
\hline \multirow[t]{3}{*}{ L126A } & 376 & G (47) & $\mathrm{T}(14)$ & $\mathrm{T}(25)$ & & $\mathrm{T}(50)$ & & 11.3 & 18.4 & 0.0 & $* *$ \\
\hline & 377 & $C(51)$ & $\mathrm{T}(15)$ & $\mathrm{T}(26)$ & & $\mathrm{T}(51)$ & & 12.0 & 19.2 & 0.0 & $* *$ \\
\hline & 378 & A (49) & G (15) & G (26) & & G (52) & & 11.7 & 18.8 & 0.0 & $* *$ \\
\hline \multirow[t]{3}{*}{ N131D } & 391 & G (50) & $A(13)$ & A (24) & & A (48) & & 11.7 & 19.0 & 0.0 & $* *$ \\
\hline & 392 & $A(58)$ & & $A(24)$ & & $A(47)$ & & 0.0 & 0.0 & 0.0 & \\
\hline & 393 & $C(55)$ & & $C(24)$ & & $C(44)$ & & 0.0 & 0.0 & 0.0 & \\
\hline \multirow[t]{3}{*}{$\mathrm{D} 136 \mathrm{~N}$} & 406 & $A(45)$ & G (13) & G (27) & & $\mathrm{G}(51)$ & & 12.0 & 18.4 & 0.0 & $* *$ \\
\hline & 407 & $A(58)$ & & $A(27)$ & & $A(53)$ & & 0.0 & 0.0 & 0.0 & \\
\hline & 408 & $C(58)$ & & $C(25)$ & & $C(53)$ & & 0.0 & 0.0 & 0.0 & \\
\hline \multirow[t]{3}{*}{$\mathrm{H} 156 \mathrm{D}$} & 466 & G (36) & C (14) & $C(26)$ & & C (48) & & 9.8 & 14.9 & 0.0 & $* *$ \\
\hline & 467 & $A(50)$ & $\mathrm{G}(1)$ & $A(25)$ & $\mathrm{G}(1)$ & $A(49)$ & & 0.0 & 0.0 & 0.5 & \\
\hline & 468 & $C(43)$ & $\mathrm{T}(5)$ & $C(23)$ & & $C(44)$ & & 0.8 & 1.2 & 0.0 & $*$ \\
\hline \multirow[t]{3}{*}{ T171S } & 511 & $A(53)$ & & $A(21)$ & & $A(42)$ & & 0.0 & 0.0 & 0.0 & \\
\hline & 512 & $G(51)$ & $C(2)$ & $\mathrm{G}(21)$ & & $C(35)$ & G (7) & 0.0 & 15.9 & 10.4 & $* *$ \\
\hline & 513 & $C(56)$ & & $C(21)$ & & $C(40)$ & & 0.0 & 0.0 & 0.0 & \\
\hline
\end{tabular}




\section{Figure captions}

334 Figure 1. (a) Sampling map displaying the location of two hybrid zones. (b) Heat map of the Bay of

335 Biscay and English Channel with sampling sites of this study (black dots) and of Becquet et al.

336 (2012)(white dots). SST are monthly averages for July, for 1982, 1992, 2002 and 2012; high

337 Resolution SST data provided by the NOAA/OAR/ESRL PSD, Boulder, Colorado, USA (Reynolds et al.,

338 2007). (c) Mitochondrial haplotype frequencies at $\operatorname{cox} 1$ (data from Becquet et al., 2012, site

339 locations on panel b) and allele frequencies at the nuclear atp5c1 (this study). For panels (b) and (c),

340 the sites that are within the putative Finistère hybrid zone (Becquet et al. 2012 and unpublished

341 data) are identified with bolder outer circles.

342 Figure 2. (a) Sliding window analysis of the $\mathrm{dN} / \mathrm{dS}$ ratio along atp $5 c 1$ (window $50 \mathrm{AA}$ wide, sliding

343 every codon). The position of replacement mutations is provided on the right (grey dots), as well as

344 the position of conserved interaction sites detected by CDD (Marchler-Bauer et al., 2013) (black,

345 blue and red: interactions with core domain, delta and epsilon subunits, respectively). (b)Three-

346 dimensional model of the ATP synthase gamma subunit of Limecola balthica (I-TASSER prediction

347 based on reference contig from Gdańsk). The yellow segment represents the 46 residue-long

348 fragment bearing replacement mutations (grey dots).

349 Figure 3. Effect of temperature and pH on the stability (represented as $\Delta \Delta \mathrm{G}$ ) of the ATP synthase 350 gamma subunit. Error bars represent one standard deviation of three measures of $\Delta \Delta \mathrm{G}$ per 351 temperature, using different $\mathrm{pH}$ values (see methods). The name of replacement mutations is 352 provided on the right. 
(a)

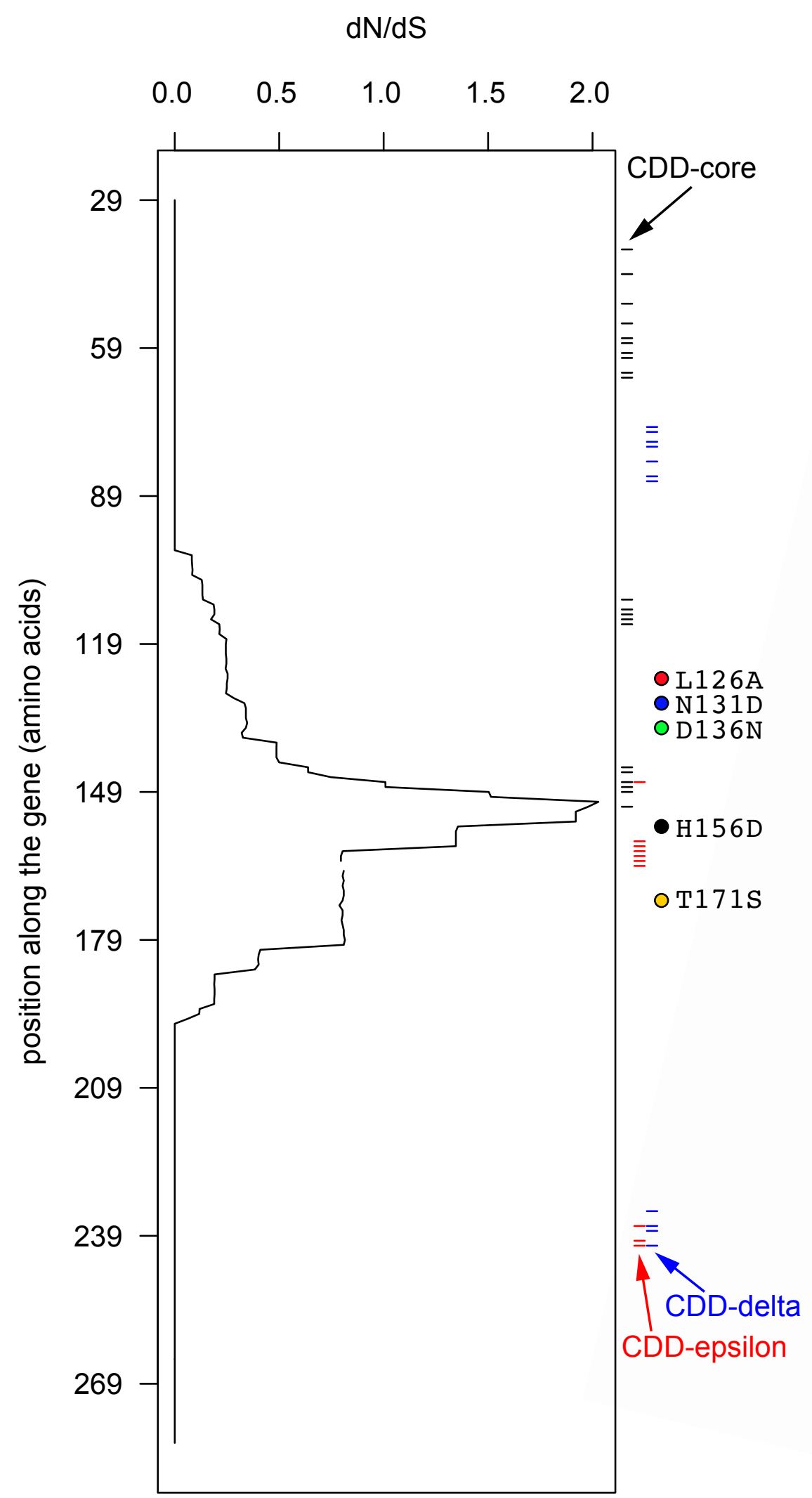

(b)

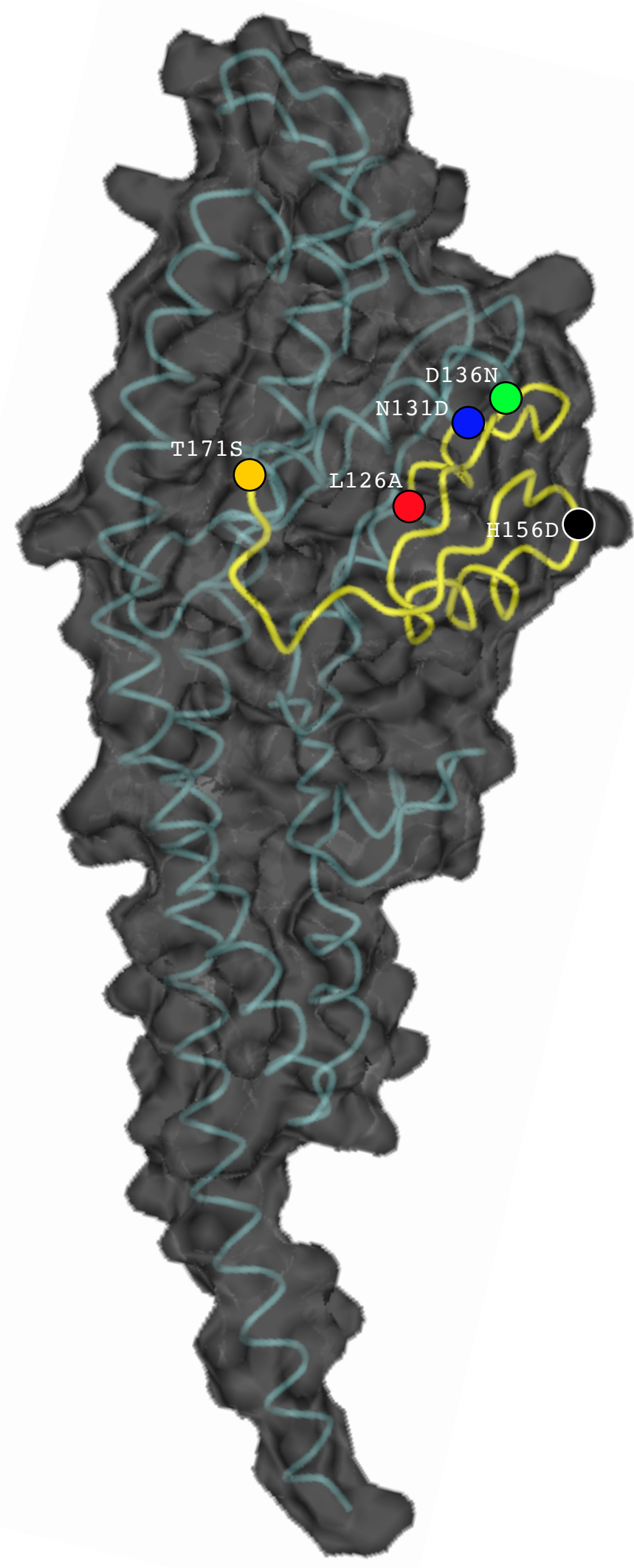




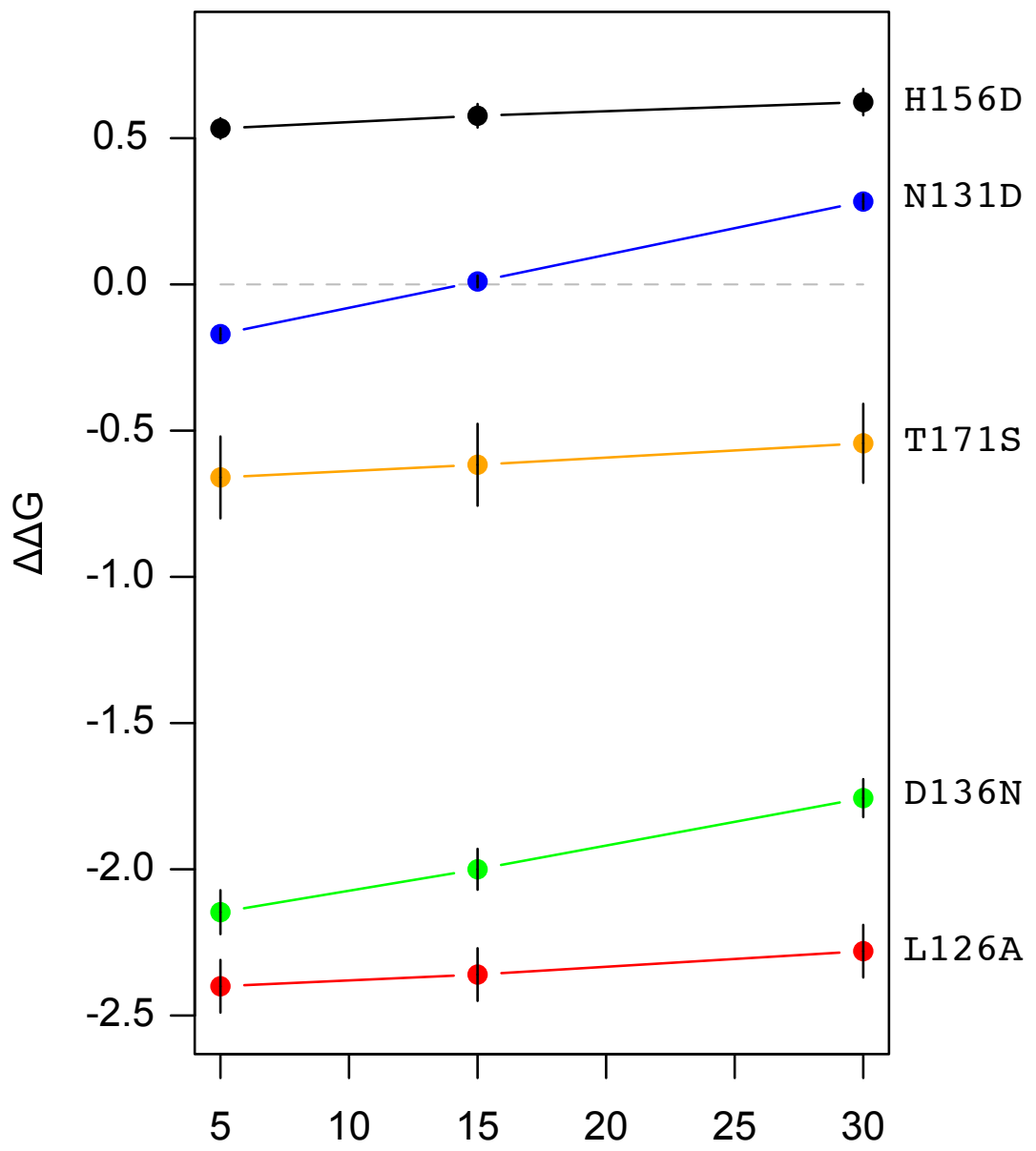

temperature $\left({ }^{\circ} \mathrm{C}\right)$ 